GU J Sci, Part C, 6(1): 91-104 (2018)

Gazi Üniversitesi
Fen Bilimleri Dergisi
PART C: TASARIM VE TEKNOLOJI
dergipark.gov.tr/http-gujsc-gazi-edu-tr

\title{
Tersine Mühendislik Yaklaşımına Dayalı Yeni Bir İmalat İçin Tasarım İşım Modeli
}

\author{
Tamer TÜRKÜCÜ ${ }^{1, * *}$, H. Rıza BÖRKLÜ² \\ ', Gazi Üniversitesi, Fen Bilimleri Enstitüsü, 06500, Teknikokullar/ANKARA \\ 2, Gazi Üniversitesi, Teknoloji Fakültesi, Endüstriyel Tasarım Mühendisliği Bölümü, 06500, Teknikokullar/ANKARA
}

\begin{abstract}
$\ddot{O} z$
Makale Bilgisi

Başvuru:09/07/2017

Düzeltme: 30/10/2017

Kabul: 20/11/2017

Mühendislik disiplini; ileriye mühendislik ve tersine mühendislik (TM) olarak ikiye ayrılır. İleriye mühendislikte süreç, problemin tanımından çözümün üretilip test edilmesi ve en iyileştirilmesi ile gelişmektedir. Tersine mühendislikte ise süreç, mevcut bir çözümün incelenip analiz edilmesi ve bunun yeniden tasarımı, geliştirilmesi ve imali şeklinde gelişmektedir. Bu çalışmada, öncelikle tersine mühendislik yöntemleri ile ilgili kaynak araştırması yapılarak mevcut yöntemler açıklanmıştır. Ayrıca, tersine mühendislik yöntemini de kullanan yeni bir imalat için tasarım işlem modeli önerilmiştir. Önerilen tasarım işlem modeli ile tasarımcılara kaliteli destek sağlanması hedeflenmiştir.
\end{abstract}

Anahtar Kelimeler

Tersine mühendislik,

Bilgisayar destekli tasarım

Imalat ve montaj için

tasarim

Keywords

Reverse engineering,

Computer-aided design,

Design for manufacturing

and assembly

\section{A Novel Design Process Model for Manufacturing Based on Reverse Engineering}

\begin{abstract}
Engineering can be classified into two groups as forward engineering (FE) and reverse engineering (RE). Forward engineering method progress from the definition of the problem to evaluation, test, and optimization of the solution. Besides, reverse engineering method progresses from examination and analysis of an existing solution thus enabling re-design, development, and manufacturing of the solution or a new solution. This study begins with a comprehensive literature review where reverse engineering methods are demonstrated. Furthermore, a new design method that also implements reverse engineering has been suggested. Suggested design process model for manufacturing can provide qualitative support for the designers to apply reverse engineering approach for their design works.
\end{abstract}

\section{GIRISŞ (INTRODUCTION)}

Mühendislik; ürün, yapı ve sistemlerin tasarım, imalat, inşa ve bakımı ile ilgilenenuzmanlık alanıdır. Mühendislik disiplini: İleriye mühendislik ve tersine mühendislik olarak ikiye ayrılabilir. İleriye mühendislik, bir sistemi soyutlama ve mantıksal tasarımdan fiziki gerçekleştirmeye dek gelişen bir süreçtir. $\mathrm{Bu}$ ise her mühendisin kullandığı problemden çözüme giden genel yol veya yöntemdir. Ancak bazı durumlarda bu yöntem zaman ve maliyet artışı gibi istenmeyen sonuçlara neden olmaktadır. Eğer mevcut bir ürün veya çözümü esas alan çalışma yapılacak ise bu durumda tersine mühendislik avantaj sağlamaktadır. Tersine mühendislik (TM), mevcut ürün ya da modele ait tasarım ve mühendislik bilgisinin analizi sonrası ürünün yeniden tasarımı, geliştirilmesi veya imal edilmesini içermektedir. TM ihtiyacı ürün geliştirme ve tasarım sürecinde başlamakta veürünün tüm yaşam döngüsü boyunca sürmektedir. TM geniş bir alana hitap etmekte ve tasarım geliştirme aracı olarak da kullanılabilmektedir. Tasarımcı TM sürecinde mevcut ürünü kopyalar veya daha üstün özelliklere sahip olacak şekilde tekrar

\footnotetext{
*Bu çalışma, 3 - 4Nisan 2017 tarihleri arasında İstanbul'da gerçekleşen "International Symposium on 3D Printing Technologies (3DPTS2017)"kongresinde sunulmuştur.

**iletişim yazarı, e-mail: tamerturkucu@gazi.edu.tr 
tasarlayabilmektedir. Bu amaçla bilgi yönetim sistemleri iyi bir şekilde kullanmak ve mühendislik bilgisinden etkin faydalanmak gerekmektedir.

Bu çalışmada yer alan konular şöyledir: Önce TM teknolojisinin kullanım alanları ve bunlara ait örnekler verilmektedir. TM yaklaşımı ve bu amaçlı ürün tasarım işlemi karşılaştırmalı olarak açıklanmaktadır. TM yaklaşımı ile geleneksel mühendislik tasarım yaklaşımı arasındaki ilişki ve İmalat ve Montaj için Tasarım (IMT)'in önemi incelenmektedir. Daha sonra, işlem planlama ve Bilgisayar Destekli İşlem Planlama (BDIP) sistem prensip ve özellikleri ele alınmakta ve bazı örnekler verilmektedir. TM yaklaşımını geliştirmek için Bilgisayar Destekli Mühendislik (BDM), IMT ve BDİP araçlarının birlikte kullanılma yöntemleri kurgulanmış ve bir model önerilmiştir. Böylece imalata uygun ürün tasarımı ve ürün geliştirme çalışmalarında tasarımcıya nitelikli destek sağlayacak bilgisayar destekli bir sisteme ait kavramsal yapı ve çalışma mantığının ana hatları formüle edilmiştir.

$\mathrm{Bu}$ çalışma ile ortaya çıkan imalat için tasarım sistemi modeli, Bilgisayar Destekli Tasarım (BDT) sistemlerindeki imalata yönelik tasarım eksikliğini gidermeyi hedeflemektedir. Çalışmanın amacı, tanitılan imalat için tasarım sisteminin ihtiyaç duyduğu ve bu sistemin içerdiği yöntemlerin işlev ve kapsamlarının incelenerek detaylı olarak bir arada sunulmasıdır. Bu yöntemler için ayrı yayınlar bulunmaktadır ancak hepsi bir arada ele alınmamıştır.

\section{TERSİNE MÜHENDİSLİK (REVERSE ENGINEERING)}

TM yaklaşımını uygulamaya olan gereksinim; parçanın teknik resim veya modelinin yokluğu, üreticinin olmaması veya parça üretiminin durdurulmuş olması gibi hallerde ortaya çıkmaktadır [1]. Çoğaltılmak ya da değiştirilmek istenen parçalara ait BDT modelleri olmamakta veya mevcut modeller ile bu parçaların imalat1 sorunlu olabilmektedir. Bu durum genelde uzun yaşam döngüsüne sahip parçalarda olmaktadır. Bir ürünün üretimi durmuş, piyasadaki yedek parça stokları tükenmiş veya istenilen süre ve uygun maliyet ile üretimi mümkün olmamaktadır. Bazı eski parça tasarımlarında BDT kullanılmamış veya ürün belgeleri eksik ya da hiç olmamaktadır. Orijinal belgeler mevcut olsa bile, bu belgeler parçadaki son değişiklikleri içermemekte veya bunlar parçanın modern imalat yöntemleri ile üretilmesi için yetersiz kalmaktadır [2]. Ayrıca:

- Parçanın teknik resmi olmasına rağmen parça değiştirildiği için teknik resim ile parça uyumsuzluğu oluşmaktadır.

- Kalite kontrolü maksadıyla parça ve BDT modelinin karşılaştırılması gerekmektedir.

- TM; ürünün tekrar aynı veya daha üstün özelliklerde ya da yeni ve özgün tasarımının yapılması maksadıyla da kullanılmaktadır.

TM süreci, genelde parçaların 3 Boyutlu (3B) bilgisayar tasarım modellerinin oluşturması ile başlamaktadır. Ama sadece geometri söz konusu olursa bu işlem bir TM basamağı olur. Çünkü aslında TM, parçalar arası ilişkilerin ve çalışma koşullarına ait bilgilerin keşfedilerek ürün belgelerinin oluşturulduğu bir mühendislik sürecidir [1]. TM sürecinin önemli adımları; geometrik model özelliklerini belirleme, ilgili yüzeyleri tasvir, modeli parçalara ayırma, basit ve serbest geometrili yüzeyler oluşturma ve hassas BDT modelleri elde etmek şeklinde izah edilmektedir [3]. Daha yalın bir ifadeyle TM; ürün tasarımı, işlevsel özelliklerin belirlenmesi, ürünün detaylı ve işlevsel modelinin yeniden oluşturulması iş ve işlemlerini içermektedir[1].

TM; makine ve yazılım mühendisliği, animasyon ve eğlence sektörü, mikroçipler, kimyasal ürünler, elektronik, eczacılık, tıp, diş hekimliği, biyomedikal, giyim gibi alanlarda çok kullanılmaktadır. Mevcut parçaları daha hızlı dijitalleştirmek için geliştirilen yöntemler TM'ye olan ilgiyi artırmıştır. TM yöntemini uygulayabilmek için mevcut üründen ölçü alma gibi basit teknikler bile yeterliyken, parça geometrilerini dijitalleştirme teknikleri ve 3B modellemede kullanılan temassız yöntemler, bu çalışmada harcanan süreyi kısaltmakta ve karmaşık parçaları daha hızlı bir şekilde 3B olarak modellemeyi mümkün kılmaktadır.

Herráez vd. görüntü algılamada fotoğraf ve mesafelerin kullanıldığı fotogrametri tekniğinin yerini, kolay kullanımı ve daha çok veri elde etmeye imkan sağlayan tarayıcı lazerlerin aldığını belirtmektedirler. Çok fazla veri olması nedeniyle veri filtre ve sadeleştirme işlemlerine ihtiyaç duyulmaktadır ve hassasiyet malzeme özelliklerine bağlıdır. Bu alandaki yetersizliklerin videogrametri yöntemi ile giderilebileceği, 
kısa aralıklarla birçok görüntü algılanabileceği ve bu yöntemin malzeme türünden etkilenmediği vurgulanmıştır. Videogrametri sonuçlarının yüksek çözünürlüklü 3B lazer tarayıcı benzeri olduğu ve mimari tarayıcıdan daha hassas sonuçlar elde edilebileceği belirtilmiştir [4]. Kaufman vd., fotoğraflardan nasıl 3B nesne modelleri oluşturulacağı konusunu incelemişlerdir [5]. Benzer 3B model oluşturma işlemi, Smoothie-3B gibi yazılımlarla [6] oldukça kolaylaşmış ve tek bir fotoğraftan bile basılabilen 3B modeller oluşturması sağlanmıştır. Fayolle vd. bir cismin yüzeyindeki noktaları yapısal bir ağaçla temsil eden bir yöntem geliştirmişlerdir. Öncelikle noktaları alt kategorilerde toplamışlar ve temel öğeleri en iyi tanımlayan noktaları bu gruplara yerleştirmişlerdir. Daha sonra ayırıcı temel öğeleri tanımlamış ve uygun temel öğeler listesine eklemişlerdir. Son olarak genetik algoritma aracılığıyla modelin orijinal noktalarla uyumunu kontrol edip uygun temel öğeleri yapraklara ve geometrik operatörleri ise alt grup başlıklarına yerleştirmişlerdir [7]. Jeon vd., birbirine benzer ürünlerin üretildiği firmalar için kavramsal tasarım sürecinde geliştirilen tasarım dokümanlarını kullanarak BDT modellerini tekrar çağıran bir sistem tasarlamak için 3B tasarım modelleri ile tasarım dokümanları arasında ilişki kurmuşlar ve böylece yeni ürün tasarım sürecini kısaltacak bir yaklaşım geliştirmişlerdir [8]. Hazır giyim sektöründeki manken tasarımlarında da TM etkin bir şekilde kullanılmaya başlanmıştır. Bu amaçla bir insan gövdesi önce koordinat ölçme cihazı ile taranıp ilişkili nokta bulutları oluşturulmakta, arkasından bu nokta bulutları bir program vasıtasıyla insan vücuduna (manken gövdesine) ait unsurlara dönüştürülmekte ve sonra da model oluşturulmaktadır. $\mathrm{Bu}$ araştırmada geliştirilen unsur tanıma algoritması ile tatminkâr sonuçlar elde edildiği belirtilmektedir [9][10]. Tariq vd., diş hekimliği implant uygulamalarında TM kullanımını ele almışlardır. Yine bu amaçla kullanılan optik tarayıcılar, tarayıcı protokolleri, 3B tasarım yazılımları ile yapılan diş hekimliği uygulamaları, eklemeli/çıkarmalı imalatla üretilebilen parça ve kaplama tekniklerini incelemişlerdir [11]. Valerga vd., kesme takımı geliştirmede TM yaklaşımı kullanmışlardır. 3B tarama aracılığıyla görsel model kısa sürede oluşturulmakta ve ardından 3B baskı ile de istenilen ölçüde parçalar üretilebilmektedir. Böylece işlevsel testler gerçekleştirilebilmektedir [12]. Lin vd., karmaşık BDT modellerini üretmek için ikiden çok parça içeren kalıp tasarımını ele almışlardır. BDT model için geliştirdikleri algoritma ile kalıp-parça yüzeyleri ve kalıp ayırma eğrilerini otomatik olarak belirlemişlerdir [13]. Chintala vd., gaz türbin kanat tasarımını iyileştirme amaçlı TM ve Sonlu Elemanlar Analizleri kullanmışlardır[14]. Biyomedikal uygulamalarda da TM oldukça fazla kullanılmaktadır. Örneğin, Majstorovic vd., anatomik özelliklere dayalı yeni bir yöntem kullanarak insan vücudundaki kemiklerin tersine mühendisliği üzerine çalışmışlardır[15].

\section{TERSINE MÜHENDİSLIK YÖNTEMLERİ (REVERSE ENGINEERING METHODOLOGY)}

TM yöntemi bir başlangıç aşamasını içermektedir. Başlangıç aşamasında TM uygulanacak ürün ile ilgili detaylı bilgiye ve belgelere ulaşılmalıdır.

TM başlangıç aşaması şu şekilde olur [16]:

1. Normal çizim, işlev, takım, aparat, işlem ve malzeme ihtiyacı gibi tüm bilgi ve belgeler toplanmaktadır.

2. Gerekli tüm yeni veri ve ayrıntılar tanımlanmaktadır.

3. Maliyet /fayda analizi yapılmaktadır.

4. Bu amaçla mümkünse tasarım mühendisi ile diyalog kurulmaktadır.

5. TM yönetim planı belirlenmektedir.

6. Kabul ölçütleri belirlenmektedir.

Başlangıç aşamasından sonra TM süreci Şekil 1'de gösterildiği gibi devam etmektedir. Önce, mevcut parça üzerinden geometrik veriler toplanmakta, bu verilere ön işlemler uygulanarak olumsuzluklar giderilmektedir. Ardından elde edilen nokta bulutuna; örnek oluşturma, keskin köşeleri giderme, topoloji/delik onarma vb. işlemler uygulanarak Stereolitografik (STL) veri elde edilmektedir. STL verisi kullanılarak otomatik olarak ya da eğri tabanlı yöntemlerle geometrik unsurlar oluşturulmaktadır. Ürün parçaları ve eksik yüzeyler tamamlanarak BDT modeli elde edilmekte ve gerekli yeni unsurlar oluşturulup model tamamlanmaktadır. BDT modeli kullanılarak, BDİ ve BDM çalışmaları yapılıp ürün imalata hazırlanmakta ve imal edilmektedir. 


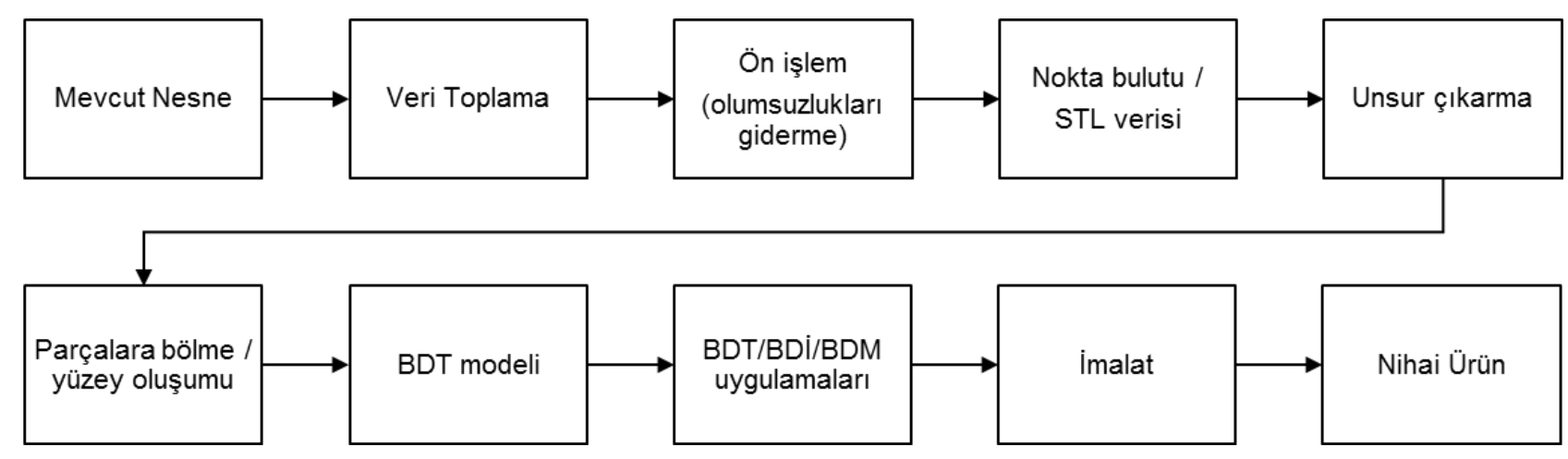

Şekil 1. Tersine mühendislik işlemlerinin genel akışşeması [3]

Ye vd. [17], Tersine Inovativ Tasarım (TIT) adlı yeni bir ürün tasarım yöntemi geliştirmiştir. Bu amaçla, SolidWorks BDT sistemine bağlı çalışan ScanTo3D isimli bir ek program hazırlamışlardır. TIT’yi 3B sayısallaştırma, 3B BDT, Bilgisayar Destekli Endüstriyel Tasarım (BDET), TM, Bilgisayar Destekli Mühendislik analizi ve hızlı prototipleme(HP) yöntemlerini içeren bütünleşik bir sayısal tasarım yöntemi olarak tanımlamışlardır. Tüm 3B BDT sistemleri unsur tabanlı tasarım yaklaşımı kullanmaktadır. Bu sistem unsur tabanlı ve parametrik bir yapıdadır, geçmişi kaydetmekte, tasarım değişikliklerini ürün ağacı altında saklamaktadır. 3B BDT sistemi ile karşılaştırıldığında BDET sistemi ile yüzey modelleme yapılabilmektedir, şekillendirme esnekliğine sahiptir, malzeme görselleştirme yapılabilmektedir, daha gerçekçi grafikler elde edilebilmektedir.

TM ve TIT modelleme stratejilerini şöyle açıklamışlardır: TM 3 farklı modelleme stratejisi içermektedir. Bunlar:

1. Serbest şekilli yüzeylerin otomatik oluşturulması

2. Unsur ve parametrik tabanlı katı model oluşturulması

3. Eğri tabanlı yüzey modellenmesi

TIT, ürünün geometrik şekline göre TM'de farklı işlemler yürüterek modelleme işlemini daha etkin yapmayı amaçlamaktadır. TIT, 3 farklı modelleme stratejisi içermektedir:

1. Organik şekiller için tanjant $\left(C^{1}\right)$ veya eğri eşleştirme $\left(C^{2}\right)$ katı modelleri ağ modelden otomatik olarak oluşturulmaktadır. Katı model, model referansları, veri aktarımı, gerçekçi grafik sunumlar ve hızlı prototip oluşturma gibi uygulama senaryolarında kullanılabilmektedir.

2. Analitik şekiller için ağ model parçalara bölünerek alt ağ olarak adlandırılan işlevsel kısımlara ayrılmaktadır. Unsur tanımlama tekniği, 3B BDT paketindeki biçim unsurlarını oluşturmada kullanılmakta ve yüksek kalitede şekil özellikleri (silindir, küre, koni, sünen/dönel yüzey) ve doğal şekil parametreleri (yarıçap, uzunluk, yükseklik ve açı) elde edilmektedir. Analitik olmayan alt ağlar B-spline yüzeyler olarak oluşturulmaktadır. Tüm bu yüzeyler, uzatılıp, kırpılıp ya da dikilerek 3B BDT yazılımı içinde katıya dönüştürülmektedir.

3. Daha hassas bir model gerekirse, eğri tabanlı modelleme stratejisi kullanılmaktadır. A $\breve{g}$ modeldeki 2B/3B taslaklar oluşturulduktan sonra sınır eğrileri ve unsur çizgileri çıkarılmaktadır. Daha sonra bu eğriler kullanılarak arakesit geçiş yüzeyleri 3B BDT yazılımında doğrudan oluşturulmaktadır.

Ayrıca, TIT temel adımları detaylı olarak şu şekilde açıklanmaktadır:

1. Fiziksel cisim ya da kil modelden 3B veri aktarımı, nokta bulutu işleme, ağ oluşturma ve ağ işlemleri yapılarak net bir ağ model elde edilmektedir.

2. Kaliteli doğal şekil ya da ürün tanım parametreleri çıkarılarak, serbest geometrili cisimlerden bile, mevcut ăg kullanılarak 3B katı model oluşturulmaktadır. Sonuçta, orijinal fiziksel cisim veya kil 
modele ait tasarım amaç ve işlevini içeren unsur tabanlı parametrik bir model BDT yazılımı içinde oluşturulmaktadır.

3. Kaliteli şekiller ve ürün tanım parametreleri, ağ yapı, yüzeyler şekillendirilip düzeltilerek yeni bir ürün modeli oluşturulmaktadır. Şekillendirmeler bölgesel veya daha geniş çaplı olabilmektedir. Bazı yüzeylerde şekillendirme işlemi çok, diğer yerlerde ise az olabilmektedir. 3B BDT yazılımındaki yeni ürün modeline ek unsurlar eklenebilmektedir. Bunların sonucunda yeni bir tasarıma ait yeni bir sayısal ürün modeli oluşturulmaktadır.

4. BDM analizi uygulanır ve analiz sonucuna göre daha önce elde edilmiş modelde istenilen tasarım değişiklikleri yapılabilmektedir. Bu tekrarlı bir süreçtir ve her adımda küçük değişiklikler yapılmaktadır. Tekrarlanan süreç sonunda yeni tasarıma ait hızlı prototip oluşturulması için kullanılabilecek en uygun sayısal model elde edilmektedir. Daha sonra, Nümerik Kontrol (NC) yazılım kodları ve teknik resim üretilmektedir.

Geleneksel TM ve TIT süreçleri Şekil 2'de karşılaştırılmaktadır. Her iki yönteme ait fiziksel nesne veya modeli sayısallaştırma işlemi benzerlik göstermektedir. Asıl fark, parça sayısal verilerinden model oluşturulmaya başlama sonrası ortaya çıkmaktadır. Yukarıda da bahsedildiği gibi TIT farklı modelleme stratejileri içermekte ve parçanın geometri ve karmaşıklığına göre farklı yöntemleri kullanmaktadır. Parça geometrisine uygun farklı modelleme stratejisi seçimi, organik şekle sahip parçalarda iyi sonuç veren yöntemlerin düzgün geometrik parçalarda hassas sonuçlar vermediği için yapılmaktadır. TIT modelde katı model oluşturma sonrası tasarım iyileştirme ve bilgisayar destekli mühendislik analiz işlemi sonucuna göre katı model değiştirilebilmektedir. Parametrik model, parametre kontrollerini kolaylaştırmakta ve böylece modeldeki değişiklikler daha iyi yapılabilmektedir. Analiz ve katı model geliştirme süreci en iyi çözüm bulunana dek sürmektedir. En iyi çözüm bulununca bu döngü tamamlanmakta ve yeni tasarım ortaya çıkmaktadır. Böylece yeni ürünün imalatına başlanabilmektedir.
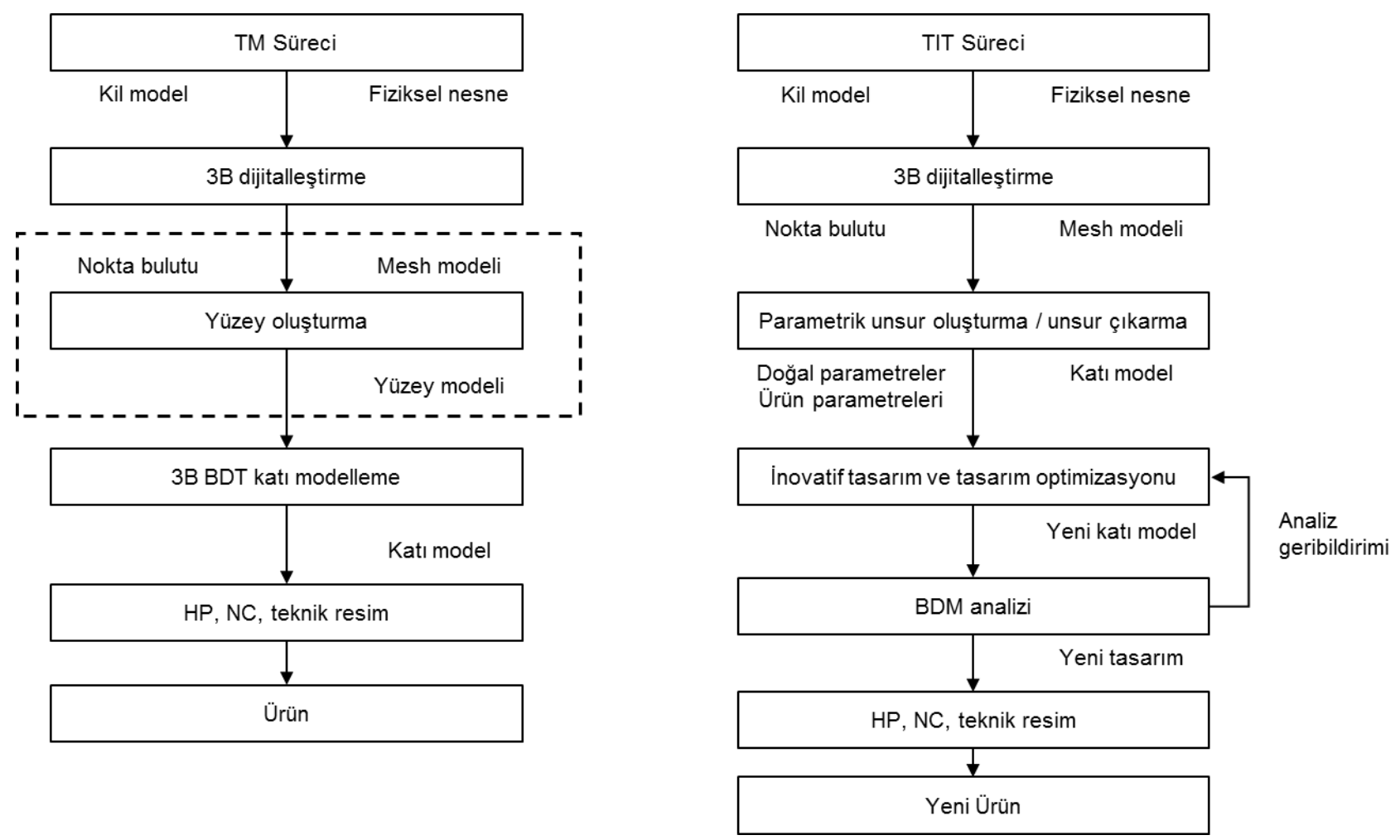

Şekil 2. TM ve TIT süreçlerinin karşılaştırılması [17]

Araştırmacılar, bu yaklaşımı Batni vd. tarafından tanıtılan TM sürecine benzetmektedir. Ye vd., TM'deki Tersine Geometrik Modelleme sürecini daha etkin hale getirmenin yanında, Germain'in açıkladığı TM başlangıç aşamasına olan bağımlılığı azaltarak TM işleminde tasarımcıyı desteklemektedir. Bu süreçte, ürün işlevlerini belirleme, malzeme seçme, maliyet/fayda analizi, imalat yöntemi, takım ve aparat gereksinimi tasarımcı tarafından yapılmaktadır. Tasarımcı, malzemesini seçimini yapmakta, analizlere ait 
ürün çalışma koşul ve işlevlerini belirlemektedir. TIT'ın yeteneklerini arttırmak, imalata yönelik tasarım kriterlerini TM süreci ile birleştirerek sağlanmaktadır. TM, aslında mühendislik tasarımının bir parçasıdır ve bu açıdan düşünüldüğünde mühendislik sürecini etkileyen faktörler TM sürecini de etkilemektedir. Makine mühendisliği tasarımında dikkate alınan bazı kriterleri Shigley Tablo 1'deki gibi listelemektedir [18]:

Tablo 1. Tasarım kriterleri

\begin{tabular}{|l|l|l|l|l|l|l|l|}
\hline 1 & İşlev & 8 & Üretilebilirlik & 15 & Stil & 22 & Pazarlanabilirlik \\
\hline 2 & Dayanım/gerilim & 9 & Yararlılık & 16 & Şekil & 23 & Bakım \\
\hline 3 & Deformasyon/sehim/katılık & 10 & Maliyet & 17 & Boyut & 24 & Hacim \\
\hline 4 & Aşınma & 11 & Sürtünme & 18 & Kontrol & 25 & Sorumluluk \\
\hline 5 & Korozyon & 12 & Ağırlık & 19 & Isıl özellikler & 26 & Sürdürülebilirlik \\
\hline 6 & Emniyet & 13 & Ömür & 20 & Yüzey & & \\
\hline 7 & Güvenilirlik & 14 & Gürültü & 21 & Yağlama & & \\
\hline
\end{tabular}

Malzeme özellikleri, geometrik özellikler, çalışma koşulları ile ilgili özellikler imalat yöntemini kısıtlayan ve imalat yöntemi ile değişebilen kriterlerdir. Messler [19]'in belirttiği üzere, mühendislik tasarım esaslarına göre yeni ürün tasarımı ve ürün geliştirme sürecinde dört temel kriter vardır: işlev, üretilebilirlik, estetik ve maliyet. Eğer bir ürün kendisi için belirlenen işlevi/görevi yerine getiremiyorsa, bunun kolay üretilebilmesi, hoş görünmesi, imalat ve işletme maliyetlerinin düşük olması önemsizdir. Bu nedenle tasarım açısından ürünün işlevi esas önem teşkil etmektedir. Ayrıca, Şekil 3'de imalata uygun tasarımı içeren iyi bir örnek yer almaktadır. Bu örnekte pnömatik piston miline takılan basit bir çatal parçanın farklı imalat yöntemlerine ait tasarım farklılıkları, hammadde şekilleri, parça ve takım maliyetleri karşılaştırmalı olarak gösterilmektedir. Burada, ürün tasarımının sadece işlevi ve amacı karşılamasının yeterli olmadığı aynı zamanda imalatı da kolaylaştırması gerektiği belirtilmektedir.

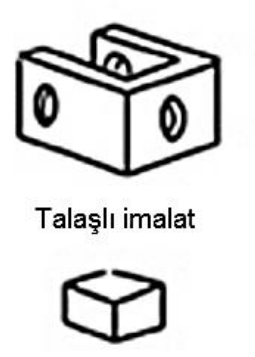

$\$ 95$

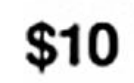

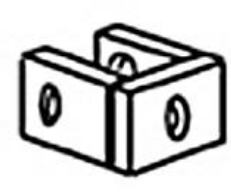

Kaynaklı imalat

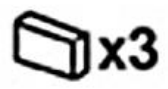

$\$ 75$

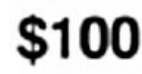

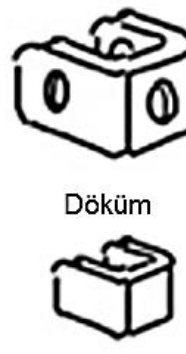

$\$ 55$

Parça adet maliyeti

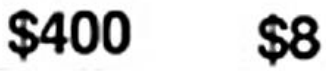

Takım maliyeti
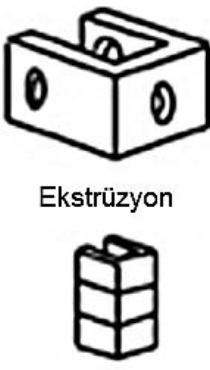

$\$ 25$
$\$ 1.20$

$\$ 0.30$
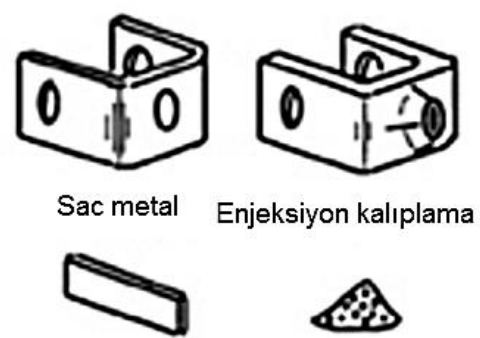

$\$ 5,000 \$ 60,000$

Şekil 3.Pnömatik piston çatal örneğine ait imalata uygun tasarım seçenekleri ve maliyetleri [19]

Boothroyd vd. [20] imalat ve montaja uygun tasarım işlemini detaylı olarak açıklamaktadır. İmalat bir ürün ya da montaja ait bir parçanın imalatı; montaj ise parçaların uygun bir şekilde birleştirilip komple bir ürün oluşturması anlamındadır. Yani, montaj bir imalat yöntemi değildir. İmalat yöntemi; talaşlı imalat, kalıpta şekil verme gibi bir işlemleri içermektedir. İmalata uygun tasarım, ürünü oluşturan parçaların imalatını kolaylaştırmak demektir. Montaja uygun tasarım, ürünü kolay birleştirilecek şekilde tasarlamayı içermektedir. Böylece imalat ve montaja uygun tasarım (İMİT), imalata uygun tasarım (İ̈T) ile montaja uygun tasarım (MIT) yöntemlerinin birleşimidir. TM ihtiyacına yol açan bir husus da tasarım esnasında imalat ve montaj yöntemlerine dikkat etmemek olduğu daha önce belirtilmişti. Bu durum, parça imalatı 
sırasında imalat mühendisi tarafından alınacak tedbir ve uygulanan çözümler ile parçada değişikliklere neden olmaktadır. İmalat mühendisince uygulanan değişikliklerin tasarım bölümüne bildirilmemesi sonucu tasarım belgeleri güncelliğini yitirmektedir. Telea vd. [21], yaptıkları kaynak taramasında, mevcut araştırmaların çoğunun TM ve hızlı prototip oluşturmayı birleştirmek olduğunu ancak TM ile İMIT'i birleştiren araştırma olmadığını belirtmiştir. Kendileri bu konuda emsal teşkil edecek bir çalışma yapmışlardır.

\section{IMMLAT ISSLEM PLANLARI (PROCESS PLANNING IN MANUFACTURING)}

IMIT'i TM sürecinde uygulayabilmek için imalat işlem planlarının tasarım sürecine dahil edilmesi gerekmektedir. Kalpakjian vd. [22], işlem planlama ile imalat işlem seçim basamaklarını Şekil 4'de göründüğü gibi tanımlamıştır. Yazarlar, geleneksel işlem planlama sürecini ana hatlarıyla açıklamış ve Bilgisayar Destekli İşlem Planlama (BDIP) sistemleri ile ilgili temel bilgiler vermiştir. İşlem planlama sürecinde takım, aparat, tezgah, işlem sırası ve montaj işlemleri belirlenmelidir. $\mathrm{Bu}$ amaçla, işlem numarası, yapılacak işlem, tezgah numarası, standart işlem süreleri ve benzer bilgiler için bir işlem belgesi oluşturulmakta ve bilgiler bu belge üzerine maddeler halinde yazılmaktadır. Bu belge, parçanın imalatı tamamlanana kadar parça ile birlikte fabrika içinde işlem görmekte ve parçaya ait imalat sürecinin takibini kolaylaştırmaktadır.

\begin{tabular}{|l|}
\hline \multicolumn{1}{|c|}{ IMALAT işLEMININ SEÇiMi } \\
\hline Iş̧ parçasının karakteristiği ve malzemesi \\
\hline İş parçasını şekli, ölçüleri ve kalınlığı \\
\hline Boyut toleransları ve yüzey kalitesi \\
\hline Parçanın işlevsel gereklilikleri \\
\hline İmalatadedi \\
\hline İmalat için otomasyon gerekliliği \\
\hline Tekil ve birleşik imalat işlem maliyetleri \\
\hline
\end{tabular}

\begin{tabular}{|l|}
\hline IŞLEM PLANLAMA \\
\hline Takım seçimi \\
\hline Aparat seçimi \\
\hline Tezgah seçimi \\
\hline İşlem sırası \\
\hline Montaj sırası \\
\hline
\end{tabular}

Şekil 4. Imalat işlem seçimi ve işlem planlama aşamaları [22]

İmalat işlem planlarının otomatik olarak oluşturulabilmesini sağlayan BDİP sistemleri, Bilgisayar Bütünleşik İmalat sistemlerinin veya daha geniş kapsamda Sayısal İmalat sistemlerinin temel araçlardan biridir. BDİP sistemleri değişken sistem ve üretken sistem olarak ikiye ayrılmaktadır [22]. Değişken sistemlerde imalat işlem planlarının saklandığı bir veri tabanı bulunmaktadır. Bir parçaya ait gerekli işlem planı sistemde bulunmazsa o parçanın imalatı için benzer işlemlere sahip başka bir parçanın planında değişiklik yapılıp yeni bir işlem planı oluşturulmaktadır. Eğer sistemde benzer bir işlem planı yoksa yeni bir işlem planı oluşturulmakta ve sistemde saklanmaktadır. Üretken sistemlerde proje planlayıcısının belirlediği yöntem sistem tarafından uygulanmakta ve parçaya ait işlem planı otomatik olarak oluşturulmaktadır. Bu sistem yeni parçaların işlem planlarının oluşturulmasında daha esnek ve kararlıdır. Karar verme mekanizması ile güncel imalat bilgilerinin sistemde kayıtlı olması işlem planlama kalitesini artırmaktadır.

Geleneksel işlem planlama sürecindeki iş yükünü azaltmayı ve işlem tasarım sürelerini kısaltmay1 amaçlayan 150'den fazla BDİP sistemi geliştirilmiştir [23]. Geliştirilen bazı BDİP sistemlerinde karar verme mekanizması uzman sistem veya yapay sinir ağları aracılığıyla yönetilmiştir [24]-[32]. BDİP sistemini çalıştırmak için imal edilecek parçaların BDT sisteminde oluşturulmuş unsur tabanlı modellerinin olması gerekmektedir. Unsurlar imalat ile ilgili bilgilerin elde edilebileceği kaynaklardır [33]. Bu amaçla BDT unsurlarının imalat unsurlarına çevrilmeleri gerekmektedir. BDT sisteminde modellenen parçalar, BDT sisteminin yapısı gereği geometri-tabanlı, unsur-tabanlı ve ortam-tabanlı yapıya sahiptir. BDİP için gerekli geometrik ve boyutsal toleranslar, yüzey kalitesi ve sertliği vb. geometrik olmayan teknik bilginin BDT sisteminde saklanması zordur. Ancak BDİP için mühendislik bilgilerini de içeren tasarım ve imalat unsurları gereklidir[34]. Xu vd. [31], ürün tasarım ve işlem planlama aşamalarını birlikte gerçekleştirebilecek nesne tabanlı bir imalat modeli geliştirmişlerdir. Bu model ile imalat bilgisi tasarımcıya aktarılabilir ve böylece tasarımcının ürün geliştirme aşamasının erken evrelerinde imal edilebilirlik ve imalat maliyeti bilgilerini değerlendirebilmesi mümkün olmaktadır. Araştırmacılar Java programlama dilini kullanarak bir Standart Query Language (SQL) veri tabanını 
yönetmişlerdir. Tasarıma ait işlem, kaynak, zaman ve maliyet bu veri tabanında saklanmıştır. Tasarım verileri bir tasarım veri tabanında saklanmış ve bu veri tabanından çağrılan tasarım adı, ana şekil, şekil karmaşıklığı, simetri, ikincil pozitif ve negatif unsurlar, ağırlık, tolerans, yüzey şartları ve üretim miktarı verileri kullanılarak aday imalat işlemleri belirlenmiştir. İmalat işlemleri belirlendikten sonra imalat süreleri de hesaplanarak uygun imalat yöntemleri belirlenmiştir. Bunlar arasından en uygun imalat yöntemi imalat maliyeti göz önünde bulundurularak seçilmektedir.

BDİP sistemleri daha önceden tanımlanmış verilere ihtiyaç duymaktadır. Bu verilerin sadece BDT modelinden elde edilmesi mümkün değildir çünkü geometri dışında boyutlar, boyutsal ve geometrik toleranslar, yüzey pürüzlülüğü ve malzeme özellikleri gibi verilere ihtiyaç duyulmaktadır [35]. Bu nedenle BDT modelindeki geometrik unsurların yanında imalat unsurlarının bilinmesi gerekmektedir. Chlebus ve Krot [35] imalat unsurlarını fonksiyonel, tasarımsal, teknolojik ve işlem unsurları olmak üzere dört farklı kısımda ele almışlardır:

- Fonksiyonel unsurlar: çekme dayanımı, ana boyutlar, tasarım, ergonomi vb.

- Tasarım unsurları: geometri, montaj, yüzey, geometrik ve boyut toleransları, malzeme

- Teknolojik unsurlar: kademe, cep boşaltma, kanal, delik vb.

- İşlem unsurları: Bir işlemde kaldırılacak talaş hacmidir.

Verdikleri kaynaklara da dayandırarak en iyi bilinen unsur tanıma tekniklerini şu şekilde belirtmişlerdir:

- Parça geometrisi tanımlama dilleri

- AAG (gelişmiş ilişski grafi)

- Sentetik şablon tanıma

- Lojik yaklaşım - kural tabanlı algoritmalar

- Nötr dosya formatından tanıma - STEP

Parça ile ilgili verilerin BDT sistemi içinde saklandığını, kullandıkları Solidworks BDT sisteminin Uygulama Programlama Arayüzü (API) aracılığıyla bu verilere ulaşılabildiğini belirtmişler ve API'nın yapısını açıklamışlardır. Araştırmacılar uygulamalarını sadece NC sistemlere yönelik gerçekleştirmişlerdir. Böyle bir avantajdan fayda sağlamak için BDT sisteminde model ile ilgili gerekli bilgilerin tasarımcı tarafından tanımlanması gerekmektedir. Yalnız teknolojik ve işlem unsurları BDT modeldeki geometrik özelliklerin analizi ile otomatik olarak elde edilebilmektedir.

Unsur tabanlı BDT modelinden imalat unsurlarının çıkarılması ve işlem planlarının oluşturulması ile ilgili çalışmalar daha çok NC imalat sistemleri hedef almış olmasına rağmen Yapısal Katı Model (CSG), IGES ve STEP yapıları kullanarak farklı yaklaşımlar uygulanmıştır [36]-[47]. Kussvd. [48] BDT modelini kullanan ve kurallara dayalı şablon tanımlama yöntemiyle, kaynaklı parçalardaki unsurların otomatik olarak tanıyabilmişlerdir. Bu sayede, geometrik unsurların seçilerek imalat unsurlarını el ile tek tek oluşturmaya gerek kalmamış, kaynaklı otomasyon işlemlerine hız kazandırırken hata yapılmasını azaltmışlardır. Yang vd. [49] unsur çıkarma ve hacim ayrıştırma tekniklerini katmanlı imalat işlemlerinde kullanmışlardır. Katmanlı imalat işlem planını esas olarak; parçayı yönlendirme, destek yapıları oluşturma, bölme ve takım yolları oluşturma aşamaları olarak tanımlamışlardır. Unsurları analiz sonucu parçanın yapısına uygun yöntem kullanılması ile yüzey kalitesinin ve imalat verimliliğinin artırıldığını göstermişlerdir.

\section{IMALAT İÇIN TASARIM IŞLEM MODELI (DESIGN PROCESS MODEL FOR MANUFACTURING)}

İmalat yöntemlerini tasnif etmek, işlem planlama ve imalat yöntemi seçimine temel oluşturmaktadır. Bu amaçla, tasarım sistemine uygun imalat yöntemlerini tasnif etmek, bunları matematiksel ilişkilerle yönetme ve geometrik ile imalat unsurları arası ilişkileri kurmak gerekmektedir. İmalat yöntemlerini tasnif amacıyla yapılan çalışmaları karşılaştıran Esmaeilian vd. [50], bu yöntemlerin yeni teknolojileri tanımlamada zor olduğu ve bunları giderecek en iyi tasnif yönteminin Nassehi vd. [51] tarafından 
yapıldığını belirtmişlerdir. Bu araştırmada anılan tasnif yöntemi esas alınmış ve imalat yöntemleri aşağıdaki gibi beşe ayrılmıştır:

1. Birleştirmeli imalat: Birden fazla parça, kaynak, montaj vb. yöntemlerle birleştirilmektedir.

2. Ayrıştırmalı imalat: Bir parça kesilerek, sökülerek ayrıştırılmaktadır.

3. Çıkartmalı imalat: Bir parçadan talaş kaldırarak parça geometrisi değiştirilmektedir.

4. Dönüştürmeli imalat: Bir parça, ağırlığı değiştirilmeden başka bir şekil veya yapıya dönüştürülmektedir.

5. Eklemeli imalat: Parça, 3B yazdırma, döküm ya da enjeksiyon kalıplama yöntemleriyle oluşturulmaktadır.

Bu tasnif yöntemi, TM sürecinde imalatı amaçlanan parçanın imalat yöntemini belirlerken, değerlendirme başlıkları azaltıldığı için süreci hızlandırmaktadır. Parçaya uyan imalat işlemleri daha hızlı belirlenebilmektedir. Daha sonra, imalat tasnif yöntemini daha ayrıntılı hale getirmek gerekmektedir. İmalat yöntemleri Kalpakjian vd. tarafından 6 farklı grupta toplanmış ve tüm yöntemler daha ayrıntılı sunulmuştur [22]. 3B modelden elde edilecek verileri değerlendirme, eşleştirme ve kıyaslama için geometrik parametreler belirlenip ve bu parametreleri tasnif edip karşılaştıracak bir sistem oluşturulabilir. $\mathrm{Bu}$ amaçla anılan iki imalat tasnif yöntemi de kullanılarak Tablo 2'de gösterildiği gibi farklı bir tasnif yöntemi elde edilmiştir.

Tablo 2. Imalat yöntemlerini tasnif etme

\begin{tabular}{|c|c|c|c|c|}
\hline Birleştirmeli imalat & Ayrıştırmalı imalat & Çıkartmalı imalat & Dönüştürmeli imalat & Eklemeli imalat \\
\hline Montaj & Demontaj & Tornalama & Haddeleme & Döküm \\
\hline Kaynak & Kesme & Frezeleme & Profil haddeleme & - Kum \\
\hline - Elektron 1şın1 & - Testere & Delme & Sicak Ekstrüzyon & - Alçı \\
\hline - MIG/MAG & - Lazer & ECM & Soğuk Ekstrüzyon & - Seramik \\
\hline - Nokta & - Su jeti & EDM & Darbeli Ekstrüzyon & • Hassas \\
\hline - Ultrasonik & - Plazma & Taşlama & Tel çekme & - Kokil \\
\hline$\bullet$ TIG & - Tel erozyon & Sac metal işleme & Çubuk çekme & - Basınçlı \\
\hline - Lazer & - Torna & Lazer & Boru çekme & 3B yazdırma \\
\hline \multirow[t]{9}{*}{ Lehim } & - Freze & Su jeti & Sac metal şekillendirme & Toz metalurjisi \\
\hline & & Plazma & Kalıpta dövme & \\
\hline & & Planya & S1cak dövme & \\
\hline & & Vargel & Soğuk dövme & \\
\hline & & Broşlama & Sivama & \\
\hline & & Honlama & Isıl işlem & \\
\hline & & Raybalama & & \\
\hline & & Borlama & & \\
\hline & & Diş açma & & \\
\hline
\end{tabular}

TM gereksinimi genellikle imalat adedi düşük, bazen bir ya da birkaç parça ile sınırlı uygulamaları kapsamaktadır. İmal edilecek parça sayısı az olmasına rağmen bu alanda çalışan tasarımcılar sürekli farklı tasarımlara sahip parçalar ile çalışmaktadırlar. İmalat adedi az ve tasarım çeşidi fazla olduğu bir süreçte tasarım çalışmaları ve tasarım doğrulamaya ayrılacak zamanda sınırlıdır. Belge eksikliği dikkate alındığında, TM tasarımcısının yeniden imal edilmesini istediği parça bilgilerini daha hızlı elde etmesine yardımcı olacak araçlara ihtiyacı vardır. 
TM tasarımcısının amacı her zaman aynı ürünü birebir imal etmek olmadığı için, tasarımcı aynı koşullarda çalışabilecek ve aynı işlevleri aynı derece veya daha işlevsel olarak yerine getirebilecek farklı bir tasarım da geliştirebilir. Daha hafif, daha dayanıklı, farklı malzeme ve işlemlerle imal edilebilecek daha ekonomik bir ürün tasarlayabilir. Şekil 5'de sunulan imalat için tasarım işlem modeli, tasarımcının bu hedefe ulaşmak için ihtiyaç duyduğu araçları sağlamayı amaçlamaktadır. Bu tasarım işlem modeli bilgi toplama, veri işleme, tasarım, analiz ve çözüm olmak üzere beş ana aşamadan oluşmaktadır. Bu aşamalar kısmen paralel ya da geriye dönük süreçler olarak da işler.

Bilgi toplama, mevcut ürün ya da varsa ürün belgelerindeki bilgiler kullanılarak başlar. Mevcut ürün üzerinden çalışma şartları, ürünün işlevi gibi bazı bilgiler alınabilir ve bu bilgiler de ürün belgelerine aktarılır. Ürün belgelerindeki bilgiler doğrudan kullanılabilir ya da değişiklik yapılarak tasarımcı girdilerine aktarılabilir. Çalışma koşulları, parçanın işlevi, yüzey kalitesi, imalat miktarı, malzeme gibi bilgiler tasarımcı tarafından girilir. Tasarımcı yeni bilgi girdiğinde ürün belgelerini de günceller. Ayrıca imalat işlemlerine ait bilgiler tüm çalışmalarda kullanılmak üzere tasarım sistemi veri tabanında saklanır.

İkinci aşamada, TM uygulanması istenilen mevcut ürünün 3B olarak sayısal ortama aktarılması işlemleri gerçekleştirilir. Bunun için temaslı ya da temassız yöntemler kullanılır. Temassız yöntemlerde gerçekleşen gelişmeler ile bu yöntemler özellikle karmaşık şekilli geometriler için değişilmez olmuştur. 3B sayısallaştırma sırasında ürün üzerinden elde edilen veriler filtre edilir ve birleştirilen nokta bulutları kullanılarak yüzey ve unsurları içeren 3B katı model elde edilir. Bu işlemler tersine geometrik modelleme alt sürecinin içinde gerçekleşir. 3B katı model geometrik verileri ve imalat verilerini içerir. 3B katı modelin unsurları geometrik veriler olduğu için daha sonra kullanılmak üzere imalat unsurlarına dönüştürülür. Geometrinin şekil karmaşıklığı analiz edilir ve en, boy, yükseklik ölçüleri ve hacim verileri ayrı parametrelere kaydedilir. Bu verilerden yararlanılarak parçanın işlenmemiş, dolu hacmi hesaplanır.

Üçüncü aşamada, ikinci aşamada 3B katı modelden elde edilen veriler ve birinci aşamadaki tasarımcı girdileri tasarım kriterleri veri tabanına aktarılmıştır ve parçanın 3B katı modeli oluşturulmuştur. 3B katı modelde eksiklikler varsa bu aşamada tamamlanır.

Dördüncü aşamada, tasarım kriterleri ve 3B katı modelden faydalanılarak işlev, dayanım, gerilim, deformasyon, sehim, katılık, ağırlık, sürtünme, termal, aşınma, korozyon gibi mühendislik hesaplamaları ve analizler gerçekleştirilir. Bunun için ürünün çalışma koşulları ve işlevi iyi anlaşılmalıdır. Ancak böylece parçaya ait malzeme, imalat toleransları ve yüzey kalitesi gibi imalat unsurları belirlenebilir.

Beşinci ve son aşamada, hesap ve analizlerden elde edilen sonuçlardan yararlanılarak tasarım gözden geçirilir ve çözümler üretilir. Malzemeyi belirlemek için mevcut ürün üzerinde test yapılabileceği gibi, parçanın çalışma koşulları ve işlevi incelenerek mühendislik hesapları ve analizlerden de yararlanılabilir. Yani başlangıçta atanan malzeme analizler sonucunda değiştirilebilir. Tüm tasarımcı girdileri ve geometriden gelen tasarım kriterleri de tasarımın gözden geçirilmesi aşamasında değerlendirilerek değiştirilebilir. Eğer çözüm yeterli bulunursa imalat işlemlerinin belirlenmesine başlanabilir ancak çözüm yeterli değilse 3B katı modelde ya da tasarım kriterlerinde düzeltmeler yapılır. Bu düzeltmeler sürecin başa dönmesini ve yeni bir tasarım oluşturulmasını gerektirir. En iyi sonuç elde edilene kadar tasarım kriterleri yeniden güncellenir, hesaplamalar ve analizler tekrarlanır. Tasarımın gözden geçirilmesi, tasarımcı girdilerinin ve 3B katı modelin eşzamanlı iyileştirilmesi ile tamamlanır.

En iyi tasarıma karar verildikten sonra imalat işlemleri belirlenir. $\mathrm{Bu}$ aşamada, imalat işlemleri veri tabanında kayıtlı hammadde şekil ve boyutları, işlem toleransları, işlem yüzey kaliteleri, takım maliyetleri, birim maliyetler ve birim süre verileri işlenir. Parçanın işlenmemiş dolu hacminin ölçüleri, imalat payları da göz önünde bulundurularak parçanın hangi ölçülerdeki ham maddelerden üretilebileceği araştırılır. Böylece, kütük, lama ya da mevcut standart bir profile sahip hammadde kullanım durumu tespit edilir. Bunun sağlanması için imalat işlemleri veri tabanı malzemelere göre standart ham madde ölçülerini içermeli ve bu bilgiler güncel ve temin edilebilir olmalıdır.

Uygun imalat işlemleri, işlem maliyetleri, işlem süreleri ve fire oranları hesaplandıktan sonra tekil ve birleşik imalat işlemleri karşılaştırmalı olarak rapor edilir. Elde edilen imalat işlem raporlarından sonra bile tasarım gözden geçirilerek tasarımcı girdileri ve 3B katı modelde değişiklik yapılabilir. Bunun için tasarımı iyileştirici sorular gözden geçirilmelidir:

- Parçanın mekanik özellikleri eksiltilebilir mi? 
- Parça toleransları bu kadar hassas olmalı mıdır?

- Daha pürüzlü yüzeyler de aynı işlevi yerine getirebilir mi?

- Boyutlar küçültülebilir mi?

- Boyutlar büyütülebilir mi?

$\mathrm{Bu}$ sorular ile birlikte tasarım tekrar gözden geçirilir, tasarım girdileri ve 3B katı modelde değişiklik yapılarak bu sefer imalata yönelik olarak tasarımın en iyileştirilmesi sağlanır. Akabinde karşılaştırmalı raporlar güncellenerek bir önceki durum ile aradaki farklar da karşılaştırılmalı olarak görüntülenir. Tasarımcı güncellenen raporları inceler ve mevcut imkanları da gözeterek en uygun imalat işlemini seçer. Seçilen bu imalat işlemlerine ait imalat çıktıları oluşturulur ve ürün imal edilir. İmalat işlemini seçimi sonrası ürün belgeleri güncellenir. İmalat işlem verileri işlenerek, gerekli ise, imalat işlemleri veri tabanı güncellenir. Böylece yapılan her çalışmada imalat işlemleri veri tabanı gelişir.

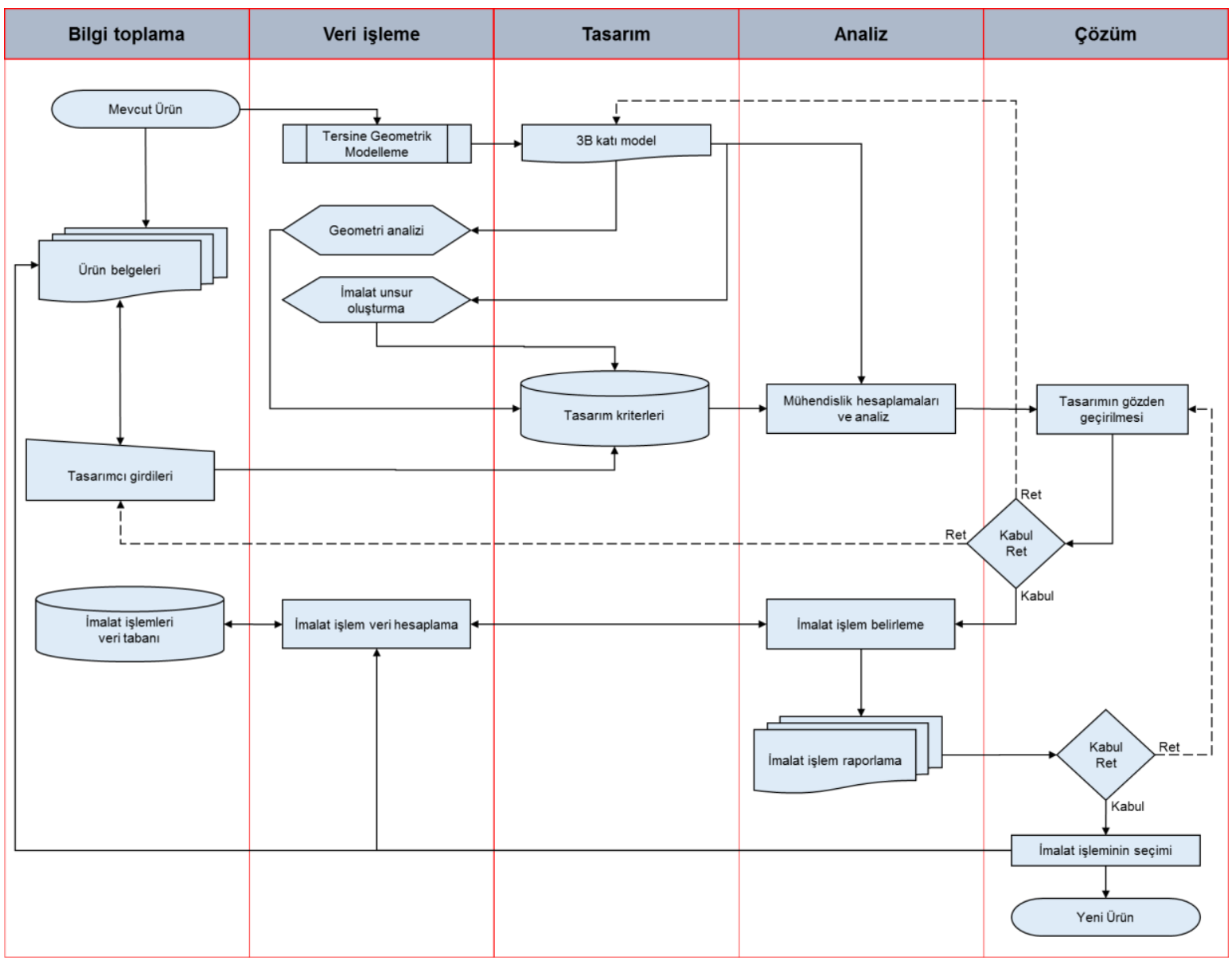

Şekil 5. Imalat için tasarım işlem modeli

\section{TARTIŞMA VE DEĞERLENDİRME (DISCUSSION AND ASSESSMENT)}

TM sürecinde klasik yöntemlerin yerini BDM araçlarıyla desteklenen yeni yöntemler almıştır. Bu süreçler de klasik mühendislik süreçleri gibi işlemektedir. Mühendislik süreçlerinde olduğu gibi gelişmiş TM süreç yeteneklerini artırmak için imalata uygun tasarım işlemleriyle beraber yapılması gerekmektedir.

$\mathrm{Bu}$ araştırmada, TM sürecinin imalat odaklı bir yapıya sahip olmasının ne şekilde mümkün olabileceği somutlaştırılmaya çalışılmıştır. TM tasarımcısının elindeki bilgileri daha kolay yönetmesi ve sonuca daha hızlı erişim sağlaması esas amaçtır. Bu kapsamda geliştirilen imalat için tasarım işlem modeli sunulmuş ve sürecin işleyişi ana detaylarıyla belirtilmeye çalışılmıştır. Ürün imalat yöntemini belirleyen tasarımcıdır. Bu nedenle imalat süreci, ürün tasarım ve geliştirme aşamasında gözetilmelidir. İmalat 
yöntemi ürünün maliyetini doğrudan etkilemektedir. Eğer tersine geometrik modelleme aşamasından başlayarak 3B modelden elde edilen bilgiler imalat bilgileri ile desteklenirse tasarımcı nihai ürünü geliştirirken daha etkili bir yol izleyebilir. İmalat unsurlarını oluşturmak ve yönetmek amacıyla, öncel imalat yöntemlerini tasnif edilmesi için bir yöntem seçilmiştir. Bu yöntem tasarım destek sistemine hız kazandırabilir. Yeni çalışmalarda bu yönteme örnek uygulamalar yapılacak ve bunun verimliliği araştırılacaktır. Tasarımcı girdilerine göre belirlenecek bilinmeyenlere ait mühendislik hesap ve analiz sonuçlarına bağlanması sağlanabilir.

\section{KAYNAKLAR (REFERENCES)}

[1] S. Batni and M. L. J. A. Tiwari, "Reverse engineering: a brief review," Int. J. Emerg. Technol., vol. 1, no. 2, pp. 73-76, 2010.

[2] W. B. Thompson, J. C. Owen, H. J. De St. Germain, S. R. Stark, and T. C. Henderson, "Featurebased reverse engineering of mechanical parts," IEEE Trans. Robot. Autom., vol. 15, no. 1, pp. 57-66, 1999.

[3] P. M. KUMAR A.; JAIN, P. K. \& PATHAK, "Reverse Engineering in Product Manufacturing: An overview," Daaam Int. Sci. B. 2013, pp. 665-678, 2013.

[4] J. Herráez, J. C. Martínez, E. Coll, M. T. Martín, and J. Rodríguez, “3D modeling by means of videogrammetry and laser scanners for reverse engineering," Measurement, vol. 87, pp. 216-227, 2016.

[5] J. Kaufman, A. E. W. Rennie, and M. Clement, "Single camera photogrammetry for reverse engineering and fabrication of ancient and modern artifacts," Procedia CIRP, vol. 36, pp. 223229, 2015.

[6] "Photo to 3D: How to Turn a Single Photo into a 3D Model \& 3D Print," 2016. [Online]. Available: https://i.materialise.com/blog/how-to-turn-a-single-photo-into-a-3d-print-with-a-freeonline-app/. [Accessed: 12-Jun-2016].

[7] P. Fayolle and A. Pasko, "An evolutionary approach to the extraction of object construction trees from 3D point clouds," Comput. Des., vol. 74, pp. 1-17, 2016.

[8] S. M. Jeon, J. H. Lee, G. J. Hahm, and H. W. Suh, "Automatic CAD model retrieval based on design documents using semantic processing and rule processing," Comput. Ind., vol. 77, pp. 29 47, 2016.

[9] C. K. Au and M. M. F. Yuen, "Feature-based reverse engineering of mannequin for garment design," Comput. Des., vol. 31, no. 12, pp. 751-759, 1999.

[10] "A study of surface reconstruction for 3D mannequins based on feature curves," Comput. Des., vol. 45, no. 11, pp. 1426-1441, Nov. 2013.

[11] T. F. Alghazzawi, "Advancements in CAD/CAM technology: Options for practical implementation," J. Prosthodont. Res., vol. 60, no. 2, pp. 72-84, 2016.

[12] A. P. Valerga, M. Batista, R. Bienvenido, S. R. Fernández-Vidal, C. Wendt, and M. Marcos, "Reverse Engineering Based Methodology for Modelling Cutting Tools," Procedia Eng., vol. 132, pp. 1144-1151, 2015.

[13] A. C. Lin and N. H. Quang, "Automatic generation of mold-piece regions and parting curves for complex CAD models in multi-piece mold design," CAD Comput. Aided Des., vol. 57, pp. 15-28, 2014.

[14] G. Chintala and P. Gudimetla, "Optimum material evaluation for gas turbine blade using Reverse 
Engineering (RE) and FEA,” Procedia Eng., vol. 97, pp. 1332-1340, 2014.

[15] V. Majstorovic, M. Trajanovic, N. Vitkovic, and M. Stojkovic, "Reverse engineering of human bones by using method of anatomical features," CIRP Ann. - Manuf. Technol., vol. 62, no. 1, pp. 167-170, 2013.

[16] H. J. de St. Germain, "Reverse Engineering Utilizing Domain Specific Knowledge," The University of Utah, 2002.

[17] X. Ye, H. Liu, L. Chen, Z. Chen, X. Pan, and S. Zhang, "Reverse innovative design - an integrated product design methodology," Comput. Des., vol. 40, pp. 812-827, 2008.

[18] J. E. Shigley, C. R. Mischke, and R. G. Budynas, Mechanical Engineering Design, vol. New York,. 2002.

[19] R. Messler, Reverse Engineering: Mechanisms, Structures, Systems \& Materials, 1st ed. Mc Graw Hill, 2014.

[20] G. Boothroyd, P. Dewhurst, and W. A. Knight, Product Design for Manufacture and Assembly. 2002.

[21] A. C. Telea, Reverse Engineering - Recent Advances and Applications. InTech, 2012.

[22] Kalpakjian S, Schmid SR. Manufacturing engineering and technology. New York; Toronto: Prentice Hall; 2010. .

[23] B. K. Choi and K. Ko, "C-space based CAPP algorithm for freeform die-cavity machining," CAD Comput. Aided Des., vol. 35, no. 2, pp. 179-189, 2003.

[24] A. Etienne, J. Y. Dantan, A. Siadat, and P. Martin, "An improved approach for automatic process plan generation of complex borings," Comput. Ind., vol. 57, no. 7, pp. 663-675, Sep. 2006.

[25] F. Gamboa Quintanilla, O. Cardin, A. L'Anton, and P. Castagna, "A Petri net-based methodology to increase flexibility in service-oriented holonic manufacturing systems," Comput. Ind., vol. 76, pp. 53-68, Feb. 2016.

[26] S. P. Leo Kumar, "State of The Art-Intense Review on Artificial Intelligence Systems Application in Process Planning and Manufacturing," Eng. Appl. Artif. Intell., vol. 65, pp. 294-329, Oct. 2017.

[27] M. a. Younis and M. a. Abdel Wahab, "A CAPP expert system for rotational components," Comput. Ind. Eng., vol. 33, no. 3-4, pp. 509-512, 1997.

[28] L. Sabourin and F. Villeneuve, "OMEGA, an expert CAPP system," Adv. Eng. Softw., vol. 25, no. 1, pp. 51-59, 1996.

[29] C. Grabowik, K. Kalinowski, and Z. Monica, "Integration of the CAD/CAPP/PPC systems," J. Mater. Process. Technol., vol. 164-165, pp. 1358-1368, 2005.

[30] J. P. Kruth, J. Detand, G. Van Zeir, J. Kempenaers, and J. Pinte, "Methods to improve the response time of a CAPP system that generates non-linear process plans," Adv. Eng. Softw., vol. 25, no. 1, pp. 9-17, 1996.

[31] S. C. Feng and E. Y. Song, "A manufacturing process information model for design and process planning integration,” J. Manuf. Syst., vol. 22, no. 1, pp. 1-15, 2003.

[32] I. Rojek, Neural Networks as Classification Models in Intelligent CAPP Systems, vol. 41, no. 3. IFAC, 2008.

[33] H. C. Lee, W. C. Jhee, and H. S. Park, "Generative CAPP through projective feature recognition," 
Comput. Ind. Eng., vol. 53, no. 2, pp. 241-246, 2007.

[34] X. Zhou, Y. Qiu, G. Hua, H. Wang, and X. Ruan, "A feasible approach to the integration of CAD and CAPP," CAD Comput. Aided Des., vol. 39, no. 4, pp. 324-338, 2007.

[35] E. Chlebus and K. Krot, "CAD 3D models decomposition in manufacturing processes," Arch. Civ. Mech. Eng., vol. 16, no. 1, pp. 20-29, 2016.

[36] L. Peled, A. Fischer, and M. Shpitalni, "Multiresolution Representation of 2D CSG Models," CIRP Ann. - Manuf. Technol., vol. 53, no. 1, pp. 143-146, Jan. 2004.

[37] B. Venu and V. R. Komma, "STEP-based feature recognition from solid models having nonplanar surfaces," Int. J. Comput. Integr. Manuf., vol. 30, no. 10, pp. 1011-1028, Oct. 2017.

[38] C. Zbiciak Rafałand Grabowik, "Feature Recognition Methods Review," in Proceedings of the 13th International Scientific Conference : Computer Aided Engineering, E. Rusiński and D. Pietrusiak, Eds. Cham: Springer International Publishing, 2017, pp. 605-615.

[39] S. Gao and J. J. Shah, "Automatic recognition of interacting machining features based on minimal condition subgraph," Comput. Des., vol. 30, no. 9, pp. 727-739, 1998.

[40] M. P. Bhandarkar and R. Nagi, "STEP-based feature extraction from STEP geometry for Agile Manufacturing," Comput. Ind., vol. 41, no. 1, pp. 3-24, 2000.

[41] Y. C. Lee and K. S. Fu, "Machine Understanding of CSG: Extraction and Unification of Manufacturing Features," IEEE Comput. Graph. Appl., vol. 7, no. 1, pp. 20-32, 1987.

[42] B. Babic, N. Nesic, and Z. Miljkovic, "A review of automated feature recognition with rule-based pattern recognition,” Comput. Ind., vol. 59, no. 4, pp. 321-337, 2008.

[43] V. B. Sunil and S. S. Pande, "Automatic recognition of features from freeform surface CAD models," CAD Comput. Aided Des., vol. 40, no. 4, pp. 502-517, 2008.

[44] A. S. M. Hoque, P. K. Halder, M. S. Parvez, and T. Szecsi, "Integrated manufacturing features and Design-for-manufacture guidelines for reducing product cost under CAD/CAM environment," Comput. Ind. Eng., vol. 66, no. 4, 2013.

[45] M. Richard, "Extraction of Feature Information From Three-Dimensional Cad Data," 1984.

[46] A. C. Lin, S.-Y. Lin, and S.-B. Cheng, "Extraction of manufacturing features from a feature-based design model," Int. J. Prod. Res., vol. 35, no. 12, pp. 3249-3288, 1997.

[47] E. S. Abouel Nasr and A. K. Kamrani, "A new methodology for extracting manufacturing features from CAD system," Comput. Ind. Eng., vol. 51, no. 3, pp. 389-415, 2006.

[48] A. Kuss, T. Dietz, K. Ksensow, and A. Verl, "Manufacturing Task Description for Robotic Welding and Automatic Feature Recognition on Product CAD Models," Procedia CIRP, vol. 60, no. 1, pp. 122-127, 2017.

[49] Y. Yang, H. T. Loh, J. Y. H. Fuh, and Y. S. Wong, "Feature extraction and volume decomposition for orthogonal layered manufacturing," CAD Comput. Aided Des., vol. 35, no. 12, pp. 1119-1128, 2003.

[50] B. Esmaeilian, S. Behdad, and B. Wang, "The evolution and future of manufacturing: A review," J. Manuf. Syst., vol. 39, pp. 79-100, 2016.

[51] "Nassehi A, Newman S, Dhokia V, Zhu Z, Asrai R. Using formal methods to model hybrid manufacturing processes. In: ElMaraghy HA, editor. Enabling manufacturing competitiveness and economic sustainability SE-8. Berlin Heidelberg: Springer; 2012. p. 52-6.” 